\title{
La observación de segundo orden y el método funcional, una mirada de gran angular en sociología
}

The second-order observation and functional method, a look of wide angle in sociology

\author{
Aldo Mauricio, Lara-Mendoza ${ }^{1}$ \\ Universidad Autónoma del Estado de México \\ Claudia Elisa, López-Miranda² \\ Universidad Autónoma Metropolitana
}

\begin{abstract}
RESUMEN
El presente artículo es producto de una revisión bibliográfica, cuyo objetivo consistió en mostrar evidencia de la relación entre el método funcional y la observación de segundo orden. Se aplicó el método de análisis, con un enfoque cualitativo, diseño no experimental, bajo un nivel documental-bibliográfico transversal. Tras la revisión documental se encontró que: Luhmann trabajó a principios de los años 70 de forma más intensa en torno al método funcional. A partir de los años 80 y hasta su muerte incorporó el cálculo de la forma de George Spencer Brown y la teoría de la second order cibernetics. Se concluye que a partir de los aportes teóricos de Luhmann y Spencer se reorganizó el método funcional.
\end{abstract}

Palabras clave: Desparadojización, Equivalencia funcional, observación de segundo orden, método funcional.

\begin{abstract}
This article is the product of a literature review, whose aim consisted in showing evidence of the relationship between the functional method and the second-order observation. The method of analysis was applied with a qualitative approach, non-experimental design, under a documentary-literature cross sectional level. After the documentary review, it was found that: Luhmann worked intensively at the beginning of the 70's, centering on the functional method. Since the 80's and until his last day, he integrated George Spencer Brown's form of calculus and the second-order cybernetics theory. It can be concluded that the functional method was reorganized from the theorical contributions of Luhmann and Spencer.
\end{abstract}

Key words: De-Paradoxofication, Fuctional Equivalent, Second-order Observation, Fuctional Method.

\section{Cómo referenciar este artículo:}

Lara-Mendoza, A, \& López-Miranda, C. E. (2017). La observación de segundo orden y el método funcional, una mirada de gran angular en sociología. Política, Globalidad y Ciudadanía, 15-33.

\section{Recibido: 02 de Julio 2016 - Aceptado: 05 de Septiembre 2016}

\section{(cc) EY-NC-ND}

$1 \quad$ Maestrante en Administración Pública y Gobierno en la Uaemex. aldomauriciolaramendoza@gmail.com

2 Doctorante en Sociología en la UAM. ely_lopezm@hotmail.com

Revista Política, Globalidad y Ciudadanía, Vol. 3 No. 5, Enero - Junio 2017, Universidad Autónoma de Nuevo León, Monterrey, México Monterrey, México, ISSN 2395-8448. pp 15-33. http://revpoliticas.uanl.mx/index.php/RPGyC/article/view/33 


\section{1- INTRODUCCIÓN}

Iniciaremos con una definición sucinta de método funcional (MF), el método funcional consiste en relacionar varias causas que son funcionalmente equivalentes para producir el mismo efecto. El presente texto tiene la intención de clarificar cómo se lleva a cabo este proceso y de responder cuál es el criterio de selección de una causa para producir cierto efecto y con relación a qué función cumple dicho efecto.

Interesa, además, enfatizar la relevancia de este método para la investigación sociológica, pues, a pesar de sus rendimientos, existe una serie de prejuicios en torno a él, que, como sostienen Marco Estrada y Edgar Guerra (2012), se deriva, en gran medida, de las críticas a la Teoría Funcionalista Parsoniana.

Se piensa que, desde el método funcional, 1) el sistema social es concebido en términos de orden y equilibrio, en este contexto, la estructura debe mantener una función (status quo); por tanto, 2) descuida el cambio y el conflicto social y 3 ) no cuenta con actores sociales auténticos sino, únicamente, con portadores de funciones sociales, a través del ejercicio de roles específicos (Estrada y Guerra, 2012: 265). A dichas objeciones, se suman las corrientes críticas, cuya vocación política impide establecer un diálogo entre sus propios marcos teóricos y otras propuestas como la autopoiesis (Maturana y Varela: 2003) o el método funcional ${ }^{3}$.

Finalmente, nos parece sustancial agregar una quinta crítica, según la cual el MF no cumple con los requerimientos mínimos de la ciencia y señalar que, justamente, uno de los objetivos del presente trabajo es refutar los cinco prejuicios mencionados, que responden, por un lado, a la presión de la vocación política y por otro, al desconocimiento de la propia lógica del método funcional. Para ello se pretende exponer, brevemente, en qué consiste el método funcional, posteriormente, daremos cuenta en qué consiste la observación de segundo orden y, por último, haremos una relación entre el método funcional y la observación de segundo orden.

\section{2- FUNDAMEDAMENTO TEÓRICO}

\section{Método Funcional}

A diferencia de los métodos de corte objetivista de la ciencia, cuya pretensión es encontrar causas fijas a efectos 'concretos', el MF problematiza las condiciones de posibilidad de cualquier fenómeno social y abstrae un criterio de referencia a partir del cual se buscan diversas soluciones. Estas soluciones, al momento de dirigirse a un mismo problema son equivalentes funcionalmente entre sí; en otras palabras, "hechos sociales que exteriormente parecen distintos, pueden ser tratados como equivalentes funcionales" (Pintos, 1999:564).

Desde este punto de vista, no basta explicar las causas por los efectos que producen, se debe tener en cuenta las razones a partir de las que los efectos se relacionan con la realización de la función de un sistema social particular, que puede ser un sistema interaccional, organizacional, algún subsistema funcional de la sociedad o un sistema de protesta (movimiento social).

Esta forma de atender los problemas se denomina funcional-estructuralista y no estructural-funcionalista. Es necesario plantear la función abstracta del sistema en un entorno o dentro de un sistema, así como el problema (también abstracto) de referencia y la equivalencia entre las posibles soluciones del mismo.

3 "Mouffe, por ejemplo, ve en Luhmann, el arquetipo ejemplar de neo-conservador tecnócrata, quien desea 'transformar problemas políticos en administrativos o técnicos' y 'restringir el campo democrático de decisiones a, cada vez más, áreas bajo el control de supuestos expertos neutros' (Mouffe, 1993, p. 48)" (Rasch, 1997: 112) [“Mou$\mathrm{ffe}$, for instance, sees in Luhmann the type of technocratic neo-conservative who wishes to "transform political problems into administrative and technical ones' and 'restrict the field of democratic decisions by turning more and more areas over to the control of supposedly neutral experts' (Mouffe, 1993, p. 48)”] Muchas veces la discusión teórica es reemplazada por atribuciones morales del tipo; neo-conservador, de derecha, tecnócrata, pro-sistema, Schmittiano, etc. Logrando, por mucho, un 'diálogo' que se puede continuar por vía de la polémica.

Revista Política, Globalidad y Ciudadanía, Vol. 3 No. 5, Enero - Junio 2017, Universidad Autónoma de Nuevo León, Monterrey, México Monterrey, México, ISSN 2395-8448. pp 15-33. http://revpoliticas.uanl.mx/index.php/RPGyC/article/view/33 
Desde un punto de vista funcional, en lugar de centrar la discusión sobre la existencia o no de las causas, por ejemplo, de si realmente existe un 'ecocídio' o si realmente hay un maltrato contra los perros, es necesario observar que cada uno de estos temas cumple la misma función para un movimiento de protesta en relación a la sociedad, a saber, de alarmar a la sociedad, lo que permite enlazar la protesta en la comunicación (Luhmann, 1998: 358-362) .

Todo ello, en contraste con la imagen común en la Sociología, de funciones mecánicas subordinadas al mantenimiento de estructuras o del status quo; en un contexto donde dichas estructuras son vistas como causas y el mantenimiento del sistema como el fin de las funciones. En la lógica del método funcional, "mantenimiento" tiene que ver con garantizar la reproducción de las operaciones, es decir, garantizar la autopoiésis, a saber, la producción de una diferencia, la diferencia entre sistema/ entorno y no alguna estructura (Luhmann, 2007: 45).

El método funcional vincula posibilidades que en un momento se encontraban aisladas, al ponerlas en estrecha relación con un problema de referencia, "el sentido del análisis funcional reside en la apertura de un ámbito de comparación" (Luhmann, 1973: 19), permite poner en equivalencia procesos que en su carácter puramente concreto no tendrían forma de ser comparados.

Desde tal punto de vista los efectos aislados aparecen como equivalentes, intercambibles entre sí, funcionales, mientras que como procesos concretos son incomparablemente distintos. Una función es por lo tanto - [...] de acuerdo con la definición de Kant - 'la unidad de la acción de ordenar diversas ideas bajo otra común’ (Luhmann, 1973: 21).

A partir de ello podemos reflexionar en torno a las relaciones entre nexos causales y preguntar por lo que se ha dejado de lado en dichas construcciones. El observador tiene que preguntarse por lo no dicho, puesto que "algo puede tener un efecto cuando está presente y cuando no está presente" (Arnold y Robles, 2000: 58). También es necesario enfatizar el carácter temporal de los elementos que se ponen en relación, ya que, siempre que se habla de las construcciones causales es relación a un sistema y en relación a la reproducción de sus elementos ${ }^{5}$.

El análisis funcional tampoco se preocupa por buscar generalizaciones, tan recurrentes en el pensamiento metafísico-ontológico. Las generalizaciones tienen por objetivo clasificar los objetos investigados, en tanto y cuanto que Son. Desde este punto de vista no tiene sentido entonces buscar lo que no son, porque se encontraría en la contextura de la Nada. El método funcional, en contraste, presupone "que algo puede ser y también no ser" (Luhmann, 1973: 23, cursivas añadidas) El valor de la función, no está dada por sí misma,

$4 \quad$ Por ejemplo; "el método que consiste en elevarse de lo abstracto a lo concreto no es sino la manera de proceder, del pensamiento para apropiarse lo concreto, para reproducirlo mentalmente como cosa concreta" (Marx, 1978: 269). Luhmann va más allá de Marx pues, con la herramienta del constructivismo operativo, se pregunta, además, por las condiciones de posibilidad de la misma abstracción. Presupone un objeto de estudio complejo y precisamente por eso, necesita de una teoría compleja para abordarlo (es decir, presupone que se trata de sistemas reales, que se describen a sí mismos); “[...] Esto excluye un programa científico que intente explicar lo concreto, así como reducir este programa, es decir, renunciar a múltiples detalles, conformarse con una comprensión aproximada de lo concreto, porque el problema no sólo reside en la complejidad inaprensible de lo concreto, sino en su discontinuidad temporal. Esta comprensión nos obliga a un cambio radical del programa científico. La pregunta central, entonces, ya no es: ¿cómo ha surgido este o aquel estado concreto? Más bien debe plantearse: ¿cómo es posible la abstracción?” (Luhmann, 1998: 266).

5 La situación es la misma cuando hablamos de un elemento como el enunciado que es parte de una formación discursiva. Esto se relaciona estrechamente con la definición funcional Foucultiana del enunciado; por su "explicación funcional: un enunciado no es una unidad sino "una función que atraviesa el campo de estructuras y las unidades posibles" (Foucault, 1972: 126 y 127)" (en Stäheli, 2008: 284) Para Foucault el análisis de la función enunciativa, consiste en estudiar al enunciado no a partir de "una relación específica que la concierne a ella misma, y no a su causa, no a sus elementos" (Foucault, 2010: 117, cursivas añadidas) sino a través de la formación discursiva de la cual forma parte y sirve.

Revista Política, Globalidad y Ciudadanía, Vol. 3 No. 5, Enero - Junio 2017, Universidad Autónoma de Nuevo León, Monterrey, México Monterrey, México, ISSN 2395-8448. pp 15-33. http://revpoliticas.uanl.mx/index.php/RPGyC/article/view/33 
no es ninguna esencia, ya que la función por sí misma es pura abstracción.

Cuando la lógica trata proposiciones incompletas, por ejemplo, “... es azul” como funciones sintácticas, ello no significa sino que de tal modo queda abier $\quad t \quad o$ un ámbito de comparación limitado, constituido por determinadas posibili d a des de completar lo que falta y convertir la oración en una verdadera declaración. "El cielo", "mi automóvil", "una violeta" son posibilidades de complemen to equivalentes a esta función. La función pura es pues una abstracción. No da ningún sentido sintáctico acabado (Luhmann, 1973: 20 y 21).

Más al ponerla en relación a una determinada formulación teórica, es posible restringir las posibilidades a las opciones que se abren, en consecuencia, los resultados se logran estructurar. El valor del MF depende de la definición precisa del punto de referencia funcional y al revés, "dicha definición tiene la misión de constituir el ámbito de equivalencia y sólo es justificable a través de esa capacidad de ordenamiento" (Luhmann, 1973: 21). De esta forma, el método funcional tiene una relación autológica con los presupuestos que evoca y lo justifican. Por un lado, el valor del mismo depende de las relaciones que despliega con referencia a la misma función que enuncia y por el otro, el análisis funcional prueba su pretensión de veracidad al compararse a sí misma con las funciones que designa en los objetos que busca aprehender.

El método funcional busca sustituir un funcionalismo de la ciencia causal, por un funcionalismo de las equivalencias (Luhmann, 1973: 23). El funcionalismo no busca justificar algún tipo de efecto y después encontrar una respectiva causa legítima que garantice la producción de tal efecto. Antes bien, la referencia a un tipo de efecto particular debe servir de estímulo para comparar y equiparar determinados hechos causales ${ }^{6}$. Pues el criterio aceptable está dado por motivos prácticos o teóricos que constituyan el foco de interés, que el método funcional "utiliza como punto de partida constante para el problema de la relación causal equivalente" (Luhmann, 1973: 26).

De la misma forma, pueden existir causas que se consideren problemáticas, por lo cual se justifica como criterio de referencia para compararlo con otras posibilidades, es decir con otras causas. Por ejemplo, si para tomar una foto se requiere de la luz del sol, se puede buscar una lámpara que cumpla la misma función, es decir, provocar una causa similar (luz) para producir un efecto equivalente (iluminar) sin tener que esperar la salida del sol.

Otro ejemplo de corte más sociológico, expuesto por Estrada Saavedra (2010: 432-434), son los diversos proyectos con miras a una formación hegemónica, por los que las comunidades indígenas modificaron su organización autopoética. Tanto la constitución del ejido como forma de producción de la vida social principalmente durante el Cardenismo, la civitas christi, instaurada por los catequistas de la diócesis de San Cristóbal, así como el intento de instaurar una mini república de masas en los ejidos con poder popular por parte de líderes maoístas y finalmente, la constitución de las comunidades indígenas como comunidades armadas rebeldes (bases de apoyo del EZLN), más que ser vistos como proyectos equivalentes para la liberación, pueden ser asumidos como equivalentes funcionales para la instauración de un orden social.

Hasta este punto, debe quedar claro que el método funcional no es solo una forma causal entre otras?

6 "La función no es ningún efecto a producir, sino un esquema lógico regulador, que organiza un ámbito de comparación de efectos equivalentes. Caracteriza una posición especial a partir de la cual pueden ser comprendidas en un aspecto unitario diversas posibilidades." (Luhmann, 1973: 20) Nosotros podríamos agregar que la función es una distinción, que busca a su vez tratar de ser la forma más clara de complejizar su objeto de estudio, a los sistemas. Explicaremos posteriormente en qué consiste la observación a partir de una distinción cuando hablemos de observación de primer y segundo orden.

7 "La metafísica de Aristóteles [...] distingue cuatro casos de causación: la formal, la material, la eficiente y la final. Todos estos casos siguen el mismo esquema inferencial, en el cual un efecto está ligado a una causa a través de una regla de transformación. Sin embargo, en el caso de la causa eficiente, la regla de transformación es usualmente interpretada como una "ley de la naturaleza", con la causa precediendo al efecto, y en el caso de la causa final, la secuencia temporal de causa y efecto se invierte: una acción ahora es causada por una meta en el futuro —un propó-

Revista Política, Globalidad y Ciudadanía, Vol. 3 No. 5, Enero - Junio 2017, Universidad Autónoma de Nuevo León, Monterrey, México Monterrey, México, ISSN 2395-8448. pp 15-33. http://revpoliticas.uanl.mx/index.php/RPGyC/article/view/33 
En este caso, la relación de subordinación se invierte, la causalidad es un "caso especial de la aplicación de categorías funcionales" (Luhmann, 1973: 10, cursivas nuestras). Esto se debe, entre otras razones, a que el funcionalismo parte de una concepción del mundo como horizonte último, es decir, como aquel entramado de remisiones irrebasable. Desde esta perspectiva el horizonte ya no es el mundo como estado objetivo donde todas las cosas se encuentran relacionadas a partir de su diferencia con el Ser y en armonía con éste. En tanto que el "Universo es, lógicamente hablando, 'mono-contextural'. Todo ahí, pertenece a la contextura universal del Ser objetivo. Y lo que no pertenece a él, es solo la nada" (Günther, 1973: 3) ${ }^{8}$.

Tampoco es aquel cosmos, ni universitas rerum donde la totalidad se relaciona a través de la naturaleza. Si se opta por tomar en cuenta la relación entre las causas y sus posibles sustituciones funcionales, resulta que "ya no es posible interpretar la causa y el efecto como determinados estados del ser y verificar la causalidad como relación invariable entre una causa y un efecto. No resulta posible justificar la exclusión de todas las otras causas y efectos" (Luhmann, 1973: 25)9.

La principal consecuencia de lo anterior es la imposibilidad de la ciencia de poder verificar todas las demás causas que podrían influenciar y producir el mismo efecto, pues al limitar el mecanismo causal a explicar un efecto a partir de una sola causa, la comprobación de "la exclusión de todos los otros factores causales no puede ser realizada efectivamente" (Luhmann, 1973: 25 y 26). Y en este punto no se puede llevar a cabo el famoso principio de falsabilidad de Popper. Pues la relación entre una causa y su efecto no es considerada de forma óntica, sino con relación a su riqueza problemática. El caso de que 'A' sea capaz de influir ' $B$ ' carece de sentido dentro del análisis funcional. Ya que de lo que se trata es de buscar si "A, C, D, E son funcionalmente equivalentes en su propiedad de influir a B" (Luhmann, 1973: 39) .

Es por esto que, para Luhmann, no existe, ni tampoco es necesario buscar, un fundamento de la reproducción de un sistema a partir de la invariabilidad de causas y efectos, el análisis funcional no procede a partir de la exclusión de todas las otras causas posibles y la designación de una, sino de la:

Inclusión. Porque no interpreta la permanencia de un sistema en términos de constantes $[\ldots]$ relaciones entre causas y efectos. Su tarea es más bien descubrir rendimientos que son equivalentes en su función de resolver problemas particulares de los sistemas. En este caso los rendimientos no necesitan tener algo en común excepto, por su puesto, su función de resolver problemas del sistema ${ }^{10}$ (Bednarz, 1984: 358).

Muchas veces se interpreta el análisis funcional como definición entre constantes y variables, cuando las mismas constantes y variables se deben buscar en los propios sistemas sociales ${ }^{11}$, o como una relación entre

sito - siendo el agente impulsor el deseo o la obediencia. La causa finalis parecería ser en la metafísica de Aristóteles el verdadero primer principio: "Todo sirve a un propósito" (Von Foerster, 1991: 95-96).

$8 \quad$ Universe is, logically speaking, "mono-contextural". Everything there is belongs to the universal contexture of objective Being. And what does not belong to it is just Nothingness.

$9 \quad$ Básicamente el mismo argumento es usado por Bednarz, "En el lenguaje de la causa y el efecto, esto significa que una función no es cumplida cuando se descubre que A causa a B sino cuando se descubre que A, C, D etc. son equivalentes en su capacidad de causar a B." (Bednarz, 1984: 349) [In the language of cause and effect this means that a function is not fulfilled when one discovers that A causes B but when one discovers that A,C,D, etc. are equivalent in their ability to cause B]

10 [inclusion because it does not interpret the permanence of a system in terms of constant (invariant) relations between causes and effects. Its task is rather to discover performances which are equivalent in their function of solving particular system problems. In this case the performances need have nothing in common except, of course, their function of solving system-problems]

11 De hecho así proceden aún muchas investigaciones, manejando variables y constantes de forma arbitraria, más bien, el analista funcional debe observar las constantes y variables que de hecho ya imponen cada sistema social. Así por ejemplo una organización incluye a un número de miembros y excluye a los que no lo son y esto lo hace independientemente si un cientista social decide investigar sólo un número arbitrario de estos miembros, en este caso, el cientista debe correlacionar sus variables y constantes con los límites que se impone la propia organización y no de

Revista Política, Globalidad y Ciudadanía, Vol. 3 No. 5, Enero - Junio 2017, Universidad Autónoma de Nuevo León, Monterrey, México Monterrey, México, ISSN 2395-8448. pp 15-33. http://revpoliticas.uanl.mx/index.php/RPGyC/article/view/33 
diversos componentes interactuantes estáticos, o como una serie de reglas a seguir y como un catálogo de funciones privilegiadas que se deben cumplir ${ }^{12}$.

Existe una estrecha relación entre el método funcional y la fenomenología Husserliana, pues ambos conciben al mundo como horizonte último de posibilidades que se diferencian y se reproducen constantemente en la actualidad operacional del sistema.

En escritos posteriores a los 80s, Luhmann se da a la tarea de incorporar los aportes de la fenomenología trascendental husserliana a la teoría de sistemas. El método funcional, por ejemplo, se relaciona con el concepto de sentido, en tanto que buscar ordenar una serie de alternativas (posibilidades que se buscan actualizar) a un problema de referencia. Sin que, de cualquier forma se busque determinar todo lo posible, dado que la remisión a más posibilidades siempre es posible.

En la contingencia y la remisión a otras posibilidades se puede observar, con claridad, la relación entre el sentido y el análisis funcional, "el método funcional comparativo y la presentación del concepto de las posibilidades problemáticas de Husserl [...] interpretan las alternativas como posibilidades determinadas de solución para un problema"13 (Bednarz, 1984: 354).

Finalmente, no hay que perder de vista, que el método funcional requiere de un marco teórico sistémico que le faculte para formular los problemas teóricos que servirán como criterios funcionales de referencia. La ganancia se obtiene de la riqueza teórica en la comparación entre rasgos estructurales entre sistemas de diverso tipo (como las organizaciones, sistemas interaccionales, sistemas funcionales, movimientos de protesta). Sin un marco teórico sólido el método funcional "operaría, por decirlo así, en un vacío" (Bednarz, 1984: 26) ${ }^{14}$. El potencial del análisis funcional va de la mano con el potencial y la relación que existe entre éste y la diferenciación sistema/ entorno de la teoría de sistemas.

En este sentido, es necesario distinguir entre referencia funcional y sistemas sociales como objetos de investigación (Luhmann, 1973: 47), con el uso del método funcional no se buscarán "problemas a secas, sino problemas para un sistema" (Galindo, 2008: 59). Los aportes de la teoría de sistemas dan pie a "superar los problemas derivados del relativismo implicado en la búsqueda de problemas" (Galindo, 2008: 59).

\section{Operación de observación}

Para esclarecer la relación entre el método funcional y la observación de segundo orden, es necesario aclarar en qué consiste la operación de la observación ${ }^{15}$. Una observación es hecha por un observador cuando este distingue algo de todo lo demás ${ }^{16}$. Cuando el observador puede sacar algo del unmarked space del

manera arbitraria.

12 De esta forma describe Bobbio el análisis estructural-funcionalista de un sistema: "Con 'sintaxis sistémica' nos referimos en cambio al conjunto de tales reglas, o sea al 'modelo' resultante de las varias 'funciones' que regulan la interacción de las partes que componen un sistema. Es a través de este concepto que nace el verdadero y propio 'sistema observante' la armazón-hipótesis que produce los instrumentos aptos para la búsqueda de las relaciones políticas empíricas que constituyen los s. [sistemas] Políticos 'reales"” (Bobbio, 1998: 25). Está de más mencionar que Bobbio entiende a los sistemas como reales/ analíticos, un prejuicio ontológico común.

13 [the comparative functional method and Husserl's presentation of the concept of problematic possibilities now becomes clear. Both interpret alternatives as definite possibilities of solution to a problem]

$14 \quad$ [would operate, as it were, in a theoretical vacuum if it was not supplemented by a theory of social systems which would "concretize", "...the class of functionally equivalent alternatives... so that explanations or predictions become possible]

15 "denominemos la reproducción de los elementos acontecibles como operación. Siempre que se hable, en lo sucesivo, de las «operaciones» de un sistema, nos referiremos a esto" (Luhmann, 1998: 68).

16 Hay que ser cuidadosos con el término "observador", pues se utiliza dicho concepto, a diferencia de "persona", "sujeto", "individuo", etc. precisamente para no reducir el alcance del mismo, pues se suele pensar en "seres humanos". Cuando hablamos de observador nos podemos referir entonces a; un sistema psíquico, un organismo vivo, una célula, el sistema nervioso, una organización, una maquina inteligente (computadora), un movimiento de protesta, un sistema social, entre otros. Un observador es entonces a todo aquél al que se le pueda atribuir una observación observable con la excepción de Dios “el diablo como observador de Dios ya no lo está; y mucho menos aún sus

Revista Política, Globalidad y Ciudadanía, Vol. 3 No. 5, Enero - Junio 2017, Universidad Autónoma de Nuevo León, Monterrey, México Monterrey, México, ISSN 2395-8448. pp 15-33. http://revpoliticas.uanl.mx/index.php/RPGyC/article/view/33 
mundo ${ }^{17}$. La forma de la observación consiste en la distinción entre indicar/ distinguir. La forma entonces tiene dos lados, el lado que se marca y el otro lado, del cual se distingue cuando se indica. Aquí la forma de la observación, del indicar distinguiendo, parece algo simple ${ }^{18}$, incluso trivial. No obstante, el asunto se vuelve sumamente complejo (no trivial) cuando observamos cómo funciona la operación de la observación. La complejidad radica en el ejercicio de observar cómo observa el observador que observa a otro observador (observación de tercer orden).

Se toma por dado que "no podemos hacer una indicación sin dibujar una distinción"19 (Spencer, 1979: 01). Cada vez que hacemos una indicación, cada vez que nombramos algo como algo, la distinción marca una diferencia en términos operativos, podemos pensar que se trata de dos operaciones. ¿Por qué puede parecernos que se trata de dos operaciones? En un principio, una operación es la de indicar (se indica algo), a pesar de que ese algo indicado, crea un límite que en el momento de ser creado es invisible para el observador. Ese límite es el que separa la indicación de lo distinguido. La operación de distinguir puede ser vista como una no-operación simultanea inobservable que se ejerce forzosamente a espaldas del observador, en sentido estricto es una no-operación (dado que no se puede estar en los dos lados, sino solo en uno, el otro lado más bien se presupone). Podemos decir que no se puede empezar con la indicación sin antes haber distinguido.

A esto se refiere Luhmann con respecto a los rames de toda distinción en la cual se trazan dos límites, el límite interior del marco, 'esto es' y el límite del mismo marco que excluye, 'esto es, no es esto otro' (Luhmann, 1995: 44). La forma de dos lados no aparece en ninguno de los lados, empero, un observador puede tratar de designarla. Cuando busca observar los dos lados el observador se ve castigado por la paradoja $^{20}$. Incluso (y con mayor razón) cuando la dirige a su propia observación, cuando se índica a sí misma: es verdad que soy un mentiroso.

El carácter autorreferencial del enunciado al referirse a sí mismo, hace de él una paradoja, pues si miento digo la verdad y si digo la verdad miento. Consecuentemente el acto de observar se tiene que dirigir a otra cosa que no sea así misma. Por lo tanto, la distinción no aparece en ninguno de los dos lados, siempre se oculta, permanece latente; "si observar es distinguir, entonces la distinción no es observable; pues no puede ser indicada ni como un lado de la distinción ni como el otro" (Luhmann, 1999: 129). Aunque claro, se puede utilizar una metaforma y distinguir distinciones (Luhmann 2007: 43 y 294). Por ejemplo, se puede distinguir un amor verdadero (a diferencia del falso) de una decisión política legítima (y no ilegítima), pero en este caso, sólo se repite el problema.

El observador en su operación de indicación no puede distinguirse a sí mismo al mismo tiempo. Consecuentemente "el observador es el parásito de su observación" (Luhmann, 1999: 129). La observación es entonces la primera diferencia que es distinguida por otro observador, que a su vez se vuelve la primera diferencia para otro, esto da como rendimiento un cálculo; "es decir una secuencia de indicaciones que, al ser cumplidas, dan determinados resultados que, para cada observador del observador, si cumple con las mismas indicaciones, serán los mismos resultados" (Luhmann, 1996: 59).

Ello podría malentenderse, pensar que apunta a interpretaciones de base intersubjetiva, sin embargo, la cuestión es más complicada. No sólo se trata de la realidad de los objetos en el mundo constatada por

competidores, los teólogos" (Luhmann, 1999: 64) Y aquél cuya observación se le pueda distinguir de otras, es decir, que su observación sea observable.

17 La misma opinión de la operación de la distinción es defendida por Maturana y Varela: "El acto de señalar cualquier ente, cosa o unidad, está amarrado a que uno realice un acto de distinción que separa a lo señalado como distinto de un fondo" (Maturana y Varela, 2003b: 24).

18 Se trata de una estructura compleja que no es observable, más que teóricamente, pues en el mundo cotidiano no es necesario darse cuenta del asunto. Por ejemplo, cuando se dice; 'el té, aún no está caliente.' ya se distinguió entre té de café, refresco etc., también lo caliente de lo frío, así como servir ahora de tener que esperar para servirlo. 19 [we cannot make an indication without drawing a distinction].

20 Para un trato de la paradoja de forma más exhaustiva ver el apartado 'Paradoja y política de la desparadojización'[QUÉ TEXTO, DÓNDE, QUÉ AÑO]

Revista Política, Globalidad y Ciudadanía, Vol. 3 No. 5, Enero - Junio 2017, Universidad Autónoma de Nuevo León, Monterrey, México Monterrey, México, ISSN 2395-8448. pp 15-33. http://revpoliticas.uanl.mx/index.php/RPGyC/article/view/33 
un 'yo' y por un 'otro yo'. No se trata entonces solo de la capacidad operativa de la distinción utilizada por los observadores y su correspondencia o no correspondencia entre sus indicaciones. Dos observadores si utilizan la misma distinción (viz, azul/ no azul) pueden constatar que el cielo es azul. Sin embargo, el principal "problema reside en la relación que las dos versiones de subjetividad tienen [...] aunque cada uno de nosotros desde su propio punto de vista es el Yo subjetivo y cualquier otro sujeto es un Tú objetivo, la situación es revertida desde el punto de vista de cualquier Tú’²1 (Günther, 1979:7).

Además del problema anterior, una de las principales razones por las que no podemos suponer una realidad intersubjetivamente consensuada o no consensuada sobre el mundo, se debe a que primeramente, la forma de sujeto/ objeto no permite que el sujeto se observe como un objeto de su propia observación. Dicho en otras palabras, no permite que el sujeto se vea en su observación como aquel residuo ineliminable de su observación, aunque solamente lo pueda hacer posteriormente. No existe una respuesta satisfactoria desde el paradigma del sujeto a esta cuestión ${ }^{22}$.

Parte del problema recae "en [...] el modelo clásico de pensar con una concomitante ontología monocontextual que no ofrece ningún lugar para el observador"23 (Günther, 1973: 4). El problema del sujeto, como mencionamos, no es solamente que la realidad intersubjetivamente construida no se pueda sostener en el paradigma de la conciencia ${ }^{24}$, sino igualmente sus lastres ontológico-teóricos y su asimetrización de la forma sujeto/ objeto que sólo permite la reflexión de uno de sus lados, a saber, del lado del sujeto. El sujeto es el único que puede conocer al mundo. No tiene entonces la forma de explicar la relación entre el 'Yo' y el 'otro Yo' y el papel de intercambio que constantemente se realiza ${ }^{25}$. Incluso en la autoobservación:

el Yo subjetivo de las formas cognitivas puede confrontarse con cualquier otro Yo en una relación de intercambio. $\mathrm{O}$, para hablar en términos más abstractos de un algoritmo: lo que es una relación (que significa un relator) debe volverse ahora un relato y lo que era previamente un relato debe elevarse a la posición de relator (Günther, 1979: 20) ${ }^{26}$

Lo que lo subordina constantemente a suponer una versión unidireccional, unilateral y parcial de la 'realidad', es decir, a una construcción intersubjetiva del mundo. Igualmente hay que tener en cuenta (y aquí se esconde la relación entre autorreferencia y heterorreferencia, que es un producto secundario de la diferencia entre sistema/ entorno) que en cualquier operación de observación se encuentra otra distinción (claro, esto

21 [problem lies in the relation both versions of subjectivity have [...] Although everyone of us from his own viewpoint is the subjective Ego and any other subject is an objective Thou the situation is reversed from the viewpoint of any Thou.]

22 Aunque claro, se puede recurrir a una solución trascendental, en versión kantiana o neokantiana.

23 [in the history of logic and of epistemology that the classic pattern of thinking with its concomitant mono-contextural ontology offered no place for the observer]

$24 \quad$ Por ejemplo Habermas da una salida a través del lenguaje. Así menciona que "un pasaje del paradigma de la filosofía de la conciencia o el paradigma de la filosofía del lenguaje consiste en un corte de la misma profundidad. A partir de este momento, los signos lingüísticos, que sirven sólo como instrumentos o equipo de las representaciones, adquieren, como reino intermediario dos significados lingüísticos, [...] Las relaciones entre lenguaje y mundo, entre proposiciones y estados de cosas, remplazan las relaciones sujeto-objeto" (Habermas, 1990:15) [A passagem do paradigma da filosofia da consciência para o paradigma da filosofia da linguagem constitui um corte de igual profundidade. A partir deste momento, os sinais lingüísticos, que serviam apenas como instrumento e equipamento das representações, adquirem, como reino intermediário dos significados lingüísticos, (...) As relações entre linguagem e mundo, entre proposição e estados de coisas, substituem as relações sujeito-objeto]

$25 \quad$ Esto no hay que confundirlo con el intercambio de roles por ejemplo, en un sistema interaccional entre espectador/ actor. Pues en este caso se trata de una condicionalización interna asimétrica que tiene otros fines según el problema de referencia y sistema de referencia. Nosotros hablamos en este punto de un problema del conocimiento. 26 [the subjective Ego of cognizance forms with any other Ego it may confront an exchange relation. Or, to speak in the more abstract terms of an algorithm: what is a relationship (which means a relator) may now become a relatum and what was previously the relatum may now be elevated to the position of a relator]

Revista Política, Globalidad y Ciudadanía, Vol. 3 No. 5, Enero - Junio 2017, Universidad Autónoma de Nuevo León, Monterrey, México Monterrey, México, ISSN 2395-8448. pp 15-33. http://revpoliticas.uanl.mx/index.php/RPGyC/article/view/33 
solo puede ser visto, cuando un observador observa la forma de la operación del observar utilizando dicha diferencia: referencia interna/externa, pero no antes ni después). Así "La referencia (lo que designa una observación), ciertamente tiene que ser distinta de la operación que refiere; pero esta distinción debe entenderse de manera puramente funcional $[. .$.$] que caracteriza únicamente la correspondiente operación de la$ observación" (Luhmann, 1996: 60). Esto es así, porque cualquier operación de observación tiene un carácter autorreferencial. Inclusive se encuentra implícito cuando un sistema se refiere sobre algo del entorno, es decir, cuando se trata de una operación (interna) heterorreferencial ${ }^{27}$. Puesto que toda operación es interna, el sistema no puede utilizar sus operaciones para tener un contacto con en el entorno. No puede superar su diferencia entre sistema/ entorno. De aquí que sea muy distinto decir, que un sistema (como el sistema sociedad) no puede entablar relaciones directas con el entorno, pero si puede comunicar sobre el entorno.

Asimismo, la relación entre la operación/ observación, es una relación de complementariedad, no es ninguna relación causal, en tanto que no podemos decir que la operación es la causa y la observación el efecto (Luhmann, 1996: 61). La operación es ciega, pues el observador no puede saber si su observación al mismo tiempo, por ejemplo, es verdadera o falsa. Esto depende de una observación posterior que se dirija a la anterior para la que vale lo mismo ${ }^{28}$. La "distinción de la frase 'A es' y 'Es verdad que A es', sólo puede ser llevada al cabo mediante una observación de la operación del conocimiento, mediante una observación del observar, en la que la primera observación 'A es', se distingue de las demás” (Luhmann, 1999: 76).

Por esta razón, los errores y las falsedades tienen la misma realidad operativa que los aciertos y verdades $^{29}$, en tanto que indicaron algo, no podían saber al mismo tiempo si su oración era acertada o verdadera, para hacerlo se necesitaba una observación posterior que se dirija a su observación para saberlo.

27 Por ejemplo, un Estado sistema político puede distinguir entre su forma de operar de la de una organización de su entorno como una ONG, entretanto no se confunden sus decisiones políticas con los comunicados de dicha organización. Puede entonces el Estado distinguir entre las comunicaciones políticas (autorreferencia) y la ONG como tema (heterorreferencia). Además no hay que perder de visión que la distinción auto/ heterorreferencia, es una construcción interna del sistema. Se lleva a cabo por operaciones internas del sistema. Por lo que la distinción "(contacto-con-el-entorno / heterorreferencia-capaz-de-enlace-sólo-interna)” (Luhmann, 2007: 66-67) no es posible. Y el observador que lo hace, lo hace con observaciones que son operaciones internas que pertenecen a un sistema.

28 "Cuando un observador opera con la distinción verdadero/falso, él no puede, al mismo tiempo, distinguir si esa operación asimismo es verdadera o falsa” (Luhmann, 1999: 76).

29 Aquí podemos distinguir entre realidad/ objetividad. La realidad "está dada con la realización de la operación" De cualquier forma "no es posible sacar conclusiones de la realidad a partir de la realización operativa de las observaciones, con respecto a su objetividad. Dicho de otra manera, la realidad de la observación no surge de una extensión hacia un mundo que exista independiente del observador" (Luhmann, 1996:62). A menos que una comunidad de observadores cometan el mismo 'error' (operacionalmente interno) de suponer una realidad que existe independientemente de ellos. Lo que nos permite constatar la operación y por tanto la realidad es la forma de "lo que sucede a diferencia de lo que no sucede. Utiliza esta diferencia consigo mismo para observar algo que no es la operación misma" (Luhmann, 1996:64). Ya mencionamos que si la observación se dirigiera a sí misma al mismo tiempo, caería en una paradoja. Lo que conduciría al observador observar su propia imposibilidad que la hace posible. O sea, tampoco la observación cuando observa un objeto puede observarse con la diferencia de lo que sucede/ no sucede. Ni puede observar al mismo tiempo el objeto que observa a diferencia de otros objetos. Estas observaciones son post-racionalizaciones. Productos de un observador de segundo orden. No disponibles en la simultaneidad, que precisamente el carácter de simultaneo significa que es in-influenciable. Además no es que la observación después cuando se dirige a una observación antes echa, pueda decir algo sobre la objetividad de la misma. Esto nunca lo puede hacer un observador, pues en su operar ninguna observación, ni la de segundo orden puede suponer que exista una realidad objetiva y otra ilusoria. Por ejemplo, hay un experimento que practica Maturana sobre una salamandra rotándole el ojo $180^{\circ}$ grados. La salamandra entonces cuando se le pone un gusano enfrente reacciona con $180^{\circ}$ de 'desviación' (desviación para un observador que distingue a la salamandra de su entorno, la salamandra misma no usa esta distinción). La pregunta es sí la salamandra aprendería a corregir su puntería. Sin embargo ya la misma manera de formular la pregunta es auto-engañadora para el biólogo que se la formula. Entonces podíamos decir que la salamandra "se equivoca, (...) está apuntando a un gusano ilusorio: (...) está confundiendo ilusión con realidad" pero la misma distinción ilusión/ realidad es en sí misma ilusoria. Lo que pasaba era que "el cerebro de la salamandra en su operar no se equivoca, hace lo único que puede hacer y en su operar no tiene sentido (...) [la] equivocación. La salamandra no tiene cómo distinguir en su experiencia visual entre gusano real y uno ilusorio, y nosotros tampoco" (Maturana, 2009: 187).

Revista Política, Globalidad y Ciudadanía, Vol. 3 No. 5, Enero - Junio 2017, Universidad Autónoma de Nuevo León, Monterrey, México Monterrey, México, ISSN 2395-8448. pp 15-33. http://revpoliticas.uanl.mx/index.php/RPGyC/article/view/33 
Es por estas razones que cualquier observación incluso la de segundo orden obra de forma acrítica, ingenua y ciega con respecto a su propia referencia, pues no la puede distinguir. En el momento en que indica, presupone su referencia. Cualquier intento por buscar fundamentar la forma de la distinción en la unidad de una identidad, cae en otra distinción ${ }^{30}$. Aunado a esto, el observador no puede observar ni el principio ni el final de su observación. Para lograr tal fin necesitaría de una observación posterior que le permitiera distinguir entre el comienzo y el final de su observación: “ a no ser que emplee otra distinción distinta a aquella con la que ha empezado y distinta a la que utiliza para continuar después de haber acabado" (Luhmann, 1999: 113). En ambos casos el observador es aquel objeto inobservable atado a la operación y por esta razón principal, no puede observarse al mismo tiempo. Mientras que el tiempo tiene una relación de simultaneidad con el entorno, el observador sólo puede observar el pasado o futuro en el presente. El futuro nunca llega. "'El tiempo está fuera de quicio', y es por eso que nunca hay un comienzo o un fin del tiempo" (Laclau, 1995: 94) $)^{31}$.

La solución a esta paradoja de la distinción se encuentra en la dimensión temporal. El tiempo es la dimensión que permite desparadojizar la paradoja de la distinción. Igualmente, para cualquier operación, el pasar de un lado de la forma al otro lado se usa inevitablemente tiempo:

De forma que, para cualquier observador el tiempo está dado antes que nada por el hecho de que toda distinción se constituye por dos lados, y para pasar de uno a otro se necesita una operación y con ella también se precisa de tiempo. Por tanto: la diferencia entre simultaneidad y diferencia, entre antes y después es el tiempo (Zamorano, 2008: 64, cursivas nuestras).

Puesto que los dos lados de la forma están dados simultáneamente, el mundo se encuentra dado así mismo en lo simultáneo y es lo que nos permite movernos de un lado a otro de la forma. Es lo que hace que tenga sentido describir algo como temporal, porque solo tiene sentido el cruce cuando se está en un lado y se puede cruzar el límite de la forma hacia el otro lado y cuando se condiciona temporalmente este crossing.

Finalmente, la relación entre operación/ observación es una relación circular. Cualquier observación como operación es ciega, no se puede observar a sí misma. La operación es un elemento que reproduce el sistema. Pero la observación también es posible, pues de otra forma no sabríamos nada de las operaciones.

Incluso una contradicción no puede renunciar a tener un rendimiento funcional de reproducir al sistema. Puede presentarse un caso en el que la contradicción se aparezca y se llegue a un momento de indeterminación en el sistema, que permita al sistema reaccionar sin cognición ${ }^{32}$. Sin embargo, se reacciona, es decir, se logra mantener una capacidad de enlace, incluso si la capacidad de enlace es negativa.

En consecuencia, podemos decir que la autopoiésis del sistema jamás se interrumpe, a menos que el sistema cese ${ }^{33}$. En este entendido, la constante reproducción autopoiética del sistema social vuelve más

$30 \quad$ Para Spencer Brown, la forma de la observación es la distinción que consiste en indicar/ distinguir, que es ella misma la distinción entre indicar y distinguir. Se trata de una forma auto-contenida. De una diferencia, no de una identidad que le deba su condición de posibilidad a algo externo a sí misma. Aquí podemos alegar el cambio de paradigma de la teoría de sistemas; "se está hablando de la diferencia entre identidad y diferencia, y no de la identidad entre identidad y diferencia" (Luhmann, 1998: 34) Asimismo hay que tomar en cuenta que el Ser no permite distinciones, no sé puede sacar nada del Ser con respecto al ente, "Si nosotros estamos buscando distinciones, tenemos que movernos en el reino de lo particular. El Ser en general no muestra distinción alguna." (Günther, 1973: 1) [“If we are looking for distinctions we have to move into the realm of the particular. Being-in-general shows no distinctions."] Aunque hay que tener precaución, porque Luhmann, también menciona la distinción medium/ forma y variación/ selección como otras diferencias directrices. El cambio de paradigma va más allá de la distinción sistema/ entorno -para más véase la entrevista a Niklas Luhmannn, 1992.

31 ["The time is out of joint," but because of that there is never a beginning-or an end-of time.]

32 Sin cognición porque se actúa discriminando sin conocimiento del entorno. Contradicción en el sentido de una construcción semántica, no en el sentido puro de la lógica formal

33 Es el caso del carácter efímero de los sistemas interaccionales y las organizaciones que llegan a un punto en que cesan. Es posible porque se mantiene de trasfondo a la sociedad misma. Estos pueden terminar y empezar de

Revista Política, Globalidad y Ciudadanía, Vol. 3 No. 5, Enero - Junio 2017, Universidad Autónoma de Nuevo León, Monterrey, México Monterrey, México, ISSN 2395-8448. pp 15-33. http://revpoliticas.uanl.mx/index.php/RPGyC/article/view/33 
comprensible la relación operación/ observación. Porque si no es posible escapar a las operaciones del sistema y siempre que se observa se utilizan, entonces podemos entender que la relación entre ambas, es una relación circular doble que se separa por latencias:

En resumen, la correspondencia entre operación y observación es doblemente circular y ambos círculos se mantienen separados a través de latencias. Por un lado, las observaciones son operaciones que reproducen de manera autopoiética a los sistemas operativos, pero no son capaces de observarse a sí mismas. Por otro, todas las operaciones pueden observarse mediante observaciones dirigidas hacia ellas; de otro modo no sabríamos nada acerca de ellas (Luhmann, 2007: 425-426).

\section{Observación de segundo orden y método funcional}

En el apartado anterior explicamos en qué consiste la operación de observar y mencionamos implícitamente en qué consiste la observación de segundo orden, en la que profundizaremos en este aparatado, al tiempo que haremos explícita su relación con el método funcional.

La observación de segundo orden consiste en una sencilla demanda: 'Observa al observador'34 Esto significa, poner atención en la distinción que utiliza. En otras palabras, el observador de segundo orden que busca observar la distinción del observador de primer orden, para ello requiere utilizar otra distinción, si utilizara la misma distinción entonces solamente se trataría de colocar "a una serie de sujetos que contemplan el mismo mundo (nivel de la 'intersubjetividad')" (Pintos, 2004: 20), permaneciendo aún en la dimensión de observaciones de primer orden.

En contraste, el observador de segundo orden busca preguntar: ¿qué es lo que el observador de primer orden deja de lado cuando utiliza esa distinción? ¿Qué no puede ver el observador de primer orden? ¿Por qué esa distinción y no otra? Y el principal paso del observador de segundo orden es que él puede pasar de preguntas del tipo 'qué', al tipo 'cómo' (Niels, 2003: 63).

En este sentido, el observador de segundo orden puede preguntar ¿cómo observa el observador de primer orden? luego entonces también podría preguntarse sobre los presupuestos que el observador de primer orden da por sentados.

El observador de segundo orden puede buscar desparadojizar la paradoja que se encuentra en la base de la distinción del observador de primer orden. En este sentido él puede distinguir su distinción. Sin embargo, alguien se puede preguntar ¿Qué se gana con esto, de qué sirve observar cómo observa el observador de primer orden? No se gana certidumbre ciertamente. Tampoco garantías para generar o exhortar al consenso. Ni promete ninguna seguridad al observador. Mucho menos permite plantear leyes generales, al contrario, busca producir incertidumbre y tratar de normalizarla (Luhmann, 2006: 277).

Es necesario aclarar ¿cómo es posible lograr la normalización? Ya habíamos mencionado que la observación de la observación de los observadores tiene como rendimiento un cálculo, pero cabe señalar que este cálculo es de un tipo particular, a saber, un cálculo recursivo ${ }^{35}$. Entonces la realidad de las observaciones se

nuevo, precisamente porque la sociedad permanece siempre realizable. Los sistemas de interacción, las organizaciones, los subsistemas funcionales y los movimientos sociales reproducen a la sociedad, pues utilizan comunicación. Aunque estos estén condicionados por la diferencia directriz respectiva.

$34 \quad$ Así Luhmann menciona que: "Y donde el teórico trascendental buscaría en el dominio de la libertad ciertas bases incondicionales de todo conocimiento empíricamente dependiente; allí, la cibernética de las relaciones de la observación indicaría: ¡observa al observador!” (Luhmann, 1996: 61).

35 "Dado que en estos casos de clausura uno introduce el resultado de una operación de nuevo en esa misma operación, se habla de 'operaciones recursivas' (de re: de nuevo, y currere: introducir)” (Foerster, 1991: 146). Podemos entonces decir, que la recursividad reside en "(...) relacionar cada contingencia individual, como contingencia, con otras contingencias seleccionadas en el contexto de la construcción de asignaciones de probabilidad o respectivamente, redundancias" (Baecker, 2005: 29) [(...) in linking every individual contingency, as a contingency, with other, selected contingencies in the context of constructing allocations of probability or, respectively, redundancies.]

Revista Política, Globalidad y Ciudadanía, Vol. 3 No. 5, Enero - Junio 2017, Universidad Autónoma de Nuevo León, Monterrey, México Monterrey, México, ISSN 2395-8448. pp 15-33. http://revpoliticas.uanl.mx/index.php/RPGyC/article/view/33 
encuentra en la facticidad y validez de las operaciones del observador, y no se basa en buscar el consenso o disenso, es decir, tampoco consiste en la relación de "los esquemas de diferencias de otros observadores y ajustarse a sus puntos de observación" (Arnold, 2000: 95). Tampoco reside en el observar al observador mismo $^{36}$. Su garantía de realidad se encuentra en el entramado o red recursiva cerrada de observaciones.

Entonces podemos afirmar que "la operación no es posible como resultado aislado, se da mediante un cálculo recursivo de cálculos. El cálculo de cálculos conduce a valores propios ${ }^{37 \%}$ (Luhmann, 2006: 284). Cabe aclarar, no hay que confundir los valores propios del sistema y la forma en que se producen los objetos e identidades a los cuales se dirigen sus observaciones. Si bien la repetición de las designaciones condensa las identidades, esto es dentro de un entorno no idéntico, históricamente contingente, donde las circunstancias siempre son no idénticas y siempre distintas en su diferencia con el sistema ${ }^{38}$. El sistema no es capaz de penetrar operativamente hacia el entorno ${ }^{39}$. Por esta circunstancias podemos decir que debido a que en la sociedad contiene una gran variedad de auto-descripciones de sí misma ${ }^{40}$ se genera una gran masa de observaciones de las observaciones (observaciones de $2^{\circ}$ orden) que generan una realidad en la que ya no hay forma de sostener una razón vinculante, ni mucho menos hablar de un metarrelato en el cual una de las partes representaría al todo; "Uno cae siempre en nuevas distinciones de distinciones, que en todo lo que se piensa y dice siempre llevan consigo también el otro lado. Así de inflado, el mundo es una gigantesca black box" (Luhman, 2006:289)

Y sólo por la razón anterior, se hace necesarios entonces restablecer estas intransparencias e irresolubles enredos de la comunicación creada por la observación de segundo orden "y se podrá recomendar que se vuelvan transparentes por lo menos algunas estructuras de interacción y que se conformen nuevamente con una observación de primer orden, whitening the black box" (Luhman, 2006:289) ${ }^{42}$. Se vuelve a exhortar por

36 La ganancia en observar al observador es que todo lo otro se deja de lado, con esta reducción de complejidad se llega al mundo y sólo en el observar como observan otros se puede empezar a ampliar (construir) la complejidad. Hay que recordar que sólo mediante la reducción de complejidad se llega a una ampliación del conocimiento (y por tanto de la complejidad misma) (Luhmann, 1996: 125 y 126). Por ejemplo, la hoja en blanco es complejidad en bruto. Para empezar a ampliar la complejidad hay que empezar a marcar distinciones (escribir en la hoja) para comenzar a construir complejidad.

37 Esto es muy notable en un ejercicio matemático muy sencillo. Cuando se aplica la raíz cuadrada iterativamente al resultado del resultado de cualquier número, el resultado cada vez se acercara más al uno, es decir, a un valor propio (eigen).

38 Tampoco hay que olvidar que el sistema es su diferencia con el entorno. No hay que entender al sistema como si estuviera aquí y por otro lado el entorno se encuentra allá como si se tratara de identidades dadas. Como si se tratara de sujetos y objetos. Por ejemplo, es común cometer el error al suponer que "Luhmann (1996) sustituye los conceptos tradicionales de subjetividad y objetividad por los de autorreferencia y heterorreferencia." (Del Angel, 2008: 30) La respuesta de Luhmann a ese prejuicio ontológico común sería la siguiente; "sería cometer un error lógico muy simple el tener al «auto» de la autorreferencia por el observador mismo [...] El observador es la unidad de la diferencia de autorreferencia / heterorreferencia. No puede por tanto, nombrarse a sí mismo. Permanece invisible para sí mismo." (Luhmann, 2007: 27-28).

39 Se podría decir en consecuencia que"(...) el sistema como una función de sí mismo en participar con un entorno cambiante, es solo el mismo cuando nunca es el mismo. (Baecker, 2005: 94) [The system, as a function of itself in engaging with a changing environment, is only the same in never being the same]

40 Los movimientos de protesta por ejemplo tienen diversas descripciones de sí mismos: i.e., movimientos de regeneración, movimientos ambientalistas, movimientos revolucionarios, movimientos anticapitalistas, movimientos anti-globalización. Y algunas descripciones (muchas veces externas), desde el sistema ciencia como; movimientos antisistémicos, movimientos sociales y no por último movimientos de protesta, entre otros. Como ejemplo, véase, (Wall, 2005).

$41 \quad$ Esta black box, la explica de forma pedagógica Gregory Bateson: "representa todo un conjunto de partes y a esa caja le ponen un rótulo que indica lo que ese conjunto de partes se supone que hace, (...) [n]o es una explicación de cómo lo hace." (Bateson, 1998: 67)

42 Para este tipo de problemas, se dice que la sociedad ha creado una serie de instituciones, semánticas, dispositivos de inmunidad que se pueden nombrar como "entendimiento". Que va desde una identidad vinculante, hasta prescripciones terapéuticas, como cualquier tipo de exhorto a la moral, a lo normativo, que relacionan elementos de diverso género: como son, institutos de "transparencia" de la extensión de la corresponsabilidad, etc. que se encuentra

Revista Política, Globalidad y Ciudadanía, Vol. 3 No. 5, Enero - Junio 2017, Universidad Autónoma de Nuevo León, Monterrey, México Monterrey, México, ISSN 2395-8448. pp 15-33. http://revpoliticas.uanl.mx/index.php/RPGyC/article/view/33 
consiguiente a la dimensión intersubjetiva, al carácter vinculante; de lo normativo, del rol, de la persona, de los valores y como caso límite a la razón misma. Se busca volver de nuevo a la observación de primer orden para hacer transparente lo intransparente, para hacer manejable la complejidad qué sale del cálculo recursivo resultado de las observaciones de observaciones:

Se aprende por segunda vez el lenguaje. Se aprende nuevamente a distinguir entre significante y significado, entre lo presente para todos los observadores de primer orden y aquello que se pueda observar como su observación. Esta diferencia rompe con el llamado consenso con todo y los requerimientos tradicionales de sinceridad, veracidad y cumplimiento de un contrato. Hay formas operativas del sistema que funcionan porque no se les toma en serio (Luhmann, 2006: 291, cursivas nuestras).

Esto nos permite constatar dos situaciones particulares:

1) Que no se puede ver que no se puede ver lo que no se puede ver ${ }^{43} y$;2) que el observador de segundo orden puede ver lo que el observador de primer orden no puede ver ${ }^{44}$. Es necesario precisar este punto.

Es totalmente falso suponer que "si se quiere saber, hay que observar lo que sea observar. Una vez más: habría que saber lo que no se sabe para llegar a saber eso que no se sabe" (Del Angel, 2008: XII). El observador de segundo orden puede ver lo que el observador de primer orden no puede ver, justamente porque utiliza otra distinción. Es decir, el observador puede distinguir dicha distinción al utilizar otra. Pero esta distinción no le permite observar el punto ciego del observador de primer orden directamente. Solo le permite formular lo que el observador de primer orden no puede ver por medio de negaciones.

"El observador de segundo orden puede observar como observador [...] al observador de primer orden solamente cuando ve que este observador no ve que él no ve lo que no ve. Esto se puede formular (observar) solamente con la ayuda de negaciones" (Luhmann, 2007b: 26, cursivas nuestras). Si el observador de primer orden observa con la distinción útil/ inútil y dice que todos los párrocos son inútiles. El observador de segundo orden puede ver que el observador de primer orden no puede ver lo agraciado/ no agraciado de los párrocos. Precisamente porque no puede distinguir lo indistinguible con la distinción que usa en ese momento (o sea, no puede observar lo agraciado/ no agraciado en la medida en que utiliza la distinción útil/

dada en "los documentos, actas y pruebas las que ganan importancia, así en un mundo constituido en el campo de la observación de segundo orden son los entendimientos los que cobran importancia" (Luhmann, 2006: 290).

43 De la misma forma Maturana y Varela "Nuestra experiencia visual es de un espacio continuo y, a menos que hagamos estas manipulaciones ingeniosas, no percibimos que de hecho hay una discontinuidad que debería aparecer. Lo fascinante con el experimento del punto ciego es que no vemos que no vemos" (Maturana y Varela, 2003b: 8). Trivializaríamos la cuestión si suponemos de nuevo una dimensión ontológica donde los sujetos ven o no ven y cuando ven que no ven, entonces ya están viendo. El asunto es que esto se llega a saber mediante ejercicios muy específicos, pero en general partimos, en que el punto ciego es la condición de la posibilidad del observar. 44 Empero, la distinción del observador de $2^{\circ}$ orden permanece oculta pues nadie la estaría diferenciando, a menos que se trate de un observador de $3^{\circ}$ orden para el cual vale lo mismo. Es necesario esclarecer en este punto, que la observación de segundo orden no significa una "mejor" observación, o una observación prestigiada o privilegiada que le permita situarse con autoridad frente a otros observadores. Como hemos estado sosteniendo a lo largo de este artículo, tanto la observación de primer y segundo ordenes, ambas tienen un punto ciego, lo cual no les hace tener un conocimiento más justo de la realidad. Por mucho la observación de segundo orden es más reflexiva, en el sentido de la prudentia. Además podemos decir que "la ciencia no puede adjudicarse la autoridad que resultara de haber descubierto y ocupado el único acceso correcto al mundo real y poder comunicar eso a otros" (Luhmann, 1996: 78). Como muchas posiciones críticas sobre la sociedad ufanan o como la misma reputación y autoridad científica (como equivalente de la verdad) muchas veces sostiene. Tampoco podemos declararnos como aquella clase de vanguardia o intelectual orgánico qué tiene una visión más certera y por lo tanto más real de la realidad. Antes bien "el teórico del conocimiento se reconocerá como una rata dentro de un laberinto y deberá reflexionar desde qué nicho observa a las otras ratas" (Luhmann, 1999: 78). Asimismo el observador de segundo orden siempre puede regresar la distinción que se encuentra en la base de la observación y por ejemplo preguntarse si la distinción acción comunicativa/estratégica es ella misma comunicativa o estratégica.

Revista Política, Globalidad y Ciudadanía, Vol. 3 No. 5, Enero - Junio 2017, Universidad Autónoma de Nuevo León, Monterrey, México Monterrey, México, ISSN 2395-8448. pp 15-33. http://revpoliticas.uanl.mx/index.php/RPGyC/article/view/33 
inútil).

El valor de la observación de segundo orden:

resulta incomprensible si nos aferrarnos a la unidad de un sujeto cognoscente al que se enfrenta un objeto que el sujeto ve o no ve, que puede ver o puede no ver. Entonces la comprobación sólo excluye la contradicción de que el sujeto ve lo que no ve, y así sigue siendo trivial (Luhmann, 1998b: 60, cursivas nuestras) $)^{45}$

La principal tentación es regresar a la ontología monocontextual en donde las cosas se encuentran de lado del Ser o de la Nada, en la cual no vale un tercio incluido como excluido, que en este caso, se trataría de la posición de cualquier observador. Pero, la receta metodológica que el observador de segundo orden debe seguir, si quiere saber algo de cómo proceder con la distinción del observador de primer orden, es observar cómo este último desparadojiza la paradoja que se encuentra en la base de su distinción. La cual, mientras se mantenga en el nivel de contemplación, no puede ser observada. Entonces el observador de segundo orden utiliza en su distinción la forma paradoja/ desparadojización y puede utilizarla, al igual que cualquier observador, solamente designando un lado u otro lado de la forma, pues si buscara observar ambos lados, cómo se sabe, se volvería paradójica su observación, se vería castigado por ella ${ }^{46}$. Entonces el observador de segundo orden necesita, con respecto a la distinción de quién observa, "temporalizarla en una sucesión del problema (paradoja) y la solución del problema (desparadojización)" (Luhmann, 1996: 75)

De esta forma podemos conectar la observación de segundo orden con el método funcional, que nos permite observar las diversas opciones que pueden sustituirse en una relación de equivalencia y sirven para cumplir dicho fin, a saber, para la desparadojización de la paradoja del observador ${ }^{47}$. La observación de segundo orden, asimismo "puede comparar diversas observaciones, y sobre todo observaciones científicas y cotidianas desde el punto de vista de la desparadojización de su paradoja" (Luhmann, 1996: 78).

El método funcional es también una observación hecha por un observador, entonces, aquél observador que utiliza el método funcional parte de una distinción. Podemos entender la distinción del método funcional como la diferencia entre problema/ múltiples soluciones equivalentes del problema.

Dicho de otra forma, "como unidad de la diferencia de problema y múltiples soluciones equivalentes y funcionales del problema, no importando si son conocidas una o más soluciones del problema o no"48.

A decir de Luis Pintos, otra forma de observar al método funcional es a través de "la distinción 'causalidad / posibilidad'. En lugar de entender a la ciencia por sus causas, se tiene la opción de buscar los "equivalentes funcionales" (Pintos, 1999: 564) Esto abre la opción de poder responder no solo preguntas del tipo 'cómo' sino también del tipo 'qué'. Es decir, con la observación de los observadores pasamos a preguntas de tipo 'cómo’ y una vez resuelto este problema, por medio del análisis funcional podemos regresar a los

$45 \quad$ Esta confusión se repite una y otra vez a lo largo del trabajo de tesis doctoral de Juan Soto Del Angel. A lo largo de su trabajo sostiene y repite ad nauseam que la paradoja del conocimiento consisten en saber lo que no se sabe. Y procede de manera contraria a lo propuesto por Luhmann, a saber, procede trivializando la observación de segundo orden. Véase pp. (Del Angel, 2008: viii, xii, 7, 10, 50, 166, 167, 252, 319, 348, 366, 369).

46 Así por ejemplo, en el famoso mito islámico es castigado Iblis (Lucifer). Puesto que él era de los ángeles, los más queridos de Dios, hasta que Dios le dio la instrucción de adorar a Adán. Él sabía que Dios era el único digno de adoración, pero al mismo tiempo sabía que no podía desobedecer a Dios, tenía frente así una paradoja que no podía desparadojizar. En cualquier caso este se convertía en un observador de Dios: "Experimenta la instrucción como paradoja, como contradicción entre la instrucción y la propia voluntad de Dios (una distinción que él mismo inventa para explicar su comportamiento)" (Luhmann, 2009b: 219). El castigo del observador es entonces no poder observar la unidad de la distinción que a fin de cuentas es la unidad de una diferencia. Los movimientos de protesta al distinguirse de la sociedad (y en esa diferencia se encuentra la unidad de su diferencia) en lugar de descender al infierno, ascienden.

47 Que puede ser, como se ha tratado de aclarar: un sistema de protesta.

$48 \quad$ "Solamente cuando se pregunta con la precisión suficiente, se obtienen como respuesta equivalencias tangibles. ¿Cómo puede conocerse con más exactitud algo que se encuentra muy alejado? Yendo hacia allí o por medio de unos prismáticos.” (Luhmann, 2007b: 103)

Revista Política, Globalidad y Ciudadanía, Vol. 3 No. 5, Enero - Junio 2017, Universidad Autónoma de Nuevo León, Monterrey, México Monterrey, México, ISSN 2395-8448. pp 15-33. http://revpoliticas.uanl.mx/index.php/RPGyC/article/view/33 
problemas del tipo 'qué'. Si se toma en serio lo anterior, podemos decir que:

desde una perspectiva funcionalista todo lo que se deja incorporar se vuelve contingente, a saber, se lo expone a una comparación con otras posibilidades. La abstracción del problema de referencia regula el alcance de esta modalización, es decir, la proporción de diversidad que puede aún describirse como solución equivalentemente funcional del mismo problema (Luhmann, 2007b: 103).

Contingente, en el sentido de que todo aquello que entra en tensión con otras alternativas equivalentes se asimila a sí mismo como no necesario, ni tampoco imposible, que podría ser pues, de otra forma y que también podría seguir siendo como es. En este sentido, la teoría de sistemas y la second order cibernetics logra colocarse de lado de teorías con un enfoque postontológico ${ }^{49}$, por un lado, "la observación de segundo orden es una observación de primer orden especializada en la ganancia de complejidad [...] que se efectúa en la medida en que renuncia a la conformación última de validez y de seguridades ontológicas y en la medida en que no puede apelar a formas esenci[alistas]" (Luhmann, 2009: 169). Y por el otro lado, la extracción del plexo causal del método funcional vuelve cualquier solución contingente.

En este sentido, es posible argumentar que "las funciones son siempre construcciones de un observador" (Luhmann, 2007b: 103, cursivas nuestras) de otra forma presupondríamos una realidad objetiva, única y absoluta e independiente del observador ${ }^{50}$.

\section{3- METODO}

\section{Diseño}

El enfoque investigativo de la presente investigación es cualitativo, de acuerdo con Hernández, Batista y Fernández (2014) "Utiliza la recolección y análisis de los datos para afinar las preguntas de investigación o revelar nuevas interrogantes en el proceso de interpretación” (p.7).

Alcanzando un diseño no experimental "Que se realiza sin la manipulación deliberada de variables y en los que sólo se observan los fenómenos en su ambiente natural para después analizarlos” (Hernández, Batista y Fernández, 2014, p. 149).

El alcance establecido es el exploratorio "emplean cuando el objetivo consiste en examinar un tema poco estudiado o novedoso" (Hernández, Batista y Fernández, 2014, p. 91).

\section{Instrumentos}

Para la construcción del marco teórico-conceptual de la teoría del método funcional, se consultaron un total de cuarenta y dos referencias bibliográficas utilizándose como instrumento las ideas, argumentos y proyectos que fueron interpretados desde una perspectiva analítica y crítica.

\footnotetext{
49 Similar a la teorías desarrollada por Foucault, Laclau y Kosselleck, según Niels, 2003.

50 Lo que no significa que el constructivismo operativo no necesite presuponer conocimiento para abordar cualquier problema del conocimiento o de su objeto. Tampoco que el constructivismo sea un anti-realismo. No niega que exista una realidad externa, sino que la condicionalización de las construcciones internas del sistema se dan, precisamente porque no se puede conocer esta realidad externa (pues el entorno es como es). Por lo que la realidad de cualquier conocimiento se encuentra en la facticidad de sus operaciones que la hacen posible, sin la necesidad de recurrir a una instancia externa. A lo único que recurre es a los componentes que le son dados por medio de la operación del distinguir indicando, de las cuales en el entorno no existe ninguna correspondencia, ni relación punto por punto. Entonces "los constructivistas radicales ven en este paso de lo «aunque imposible» a lo «porque imposible», una radicalización liberadora que puede hacer que la reflexión de dos mil años sobre el conocimiento se tenga por inútil” (Luhmann, 1999: 71).
}

Revista Política, Globalidad y Ciudadanía, Vol. 3 No. 5, Enero - Junio 2017, Universidad Autónoma de Nuevo León, Monterrey, México Monterrey, México, ISSN 2395-8448. pp 15-33. http://revpoliticas.uanl.mx/index.php/RPGyC/article/view/33 


\section{Procedimiento}

Con relación a la comprensión del problema de la investigación se recopilan fuentes secundarias de documentos académicos. En el marco de referencia se definen los conceptos básicos relativos a las teorías del actor red y redes de internacionalización de la empresa. Una vez recopilada y analizada la información se construye el documento objeto de este trabajo. Por último, se realizan las recomendaciones y conclusiones conforme a los objetivos trazados (Lechuga, 2018, p. 196).

\section{CONCLUSIONES}

Estos argumentos son relevantes por varias razones, en primer lugar, exponen la amplitud de perspectiva que permite el MF y la observación de segundo orden, pero, por otro lado, son una muestra fehaciente de que las críticas en torno al supuesto "conservadurismo" de la teoría luhmanniana y el método funcional no tienen origen en la reflexión teórico-metodológica, sino en el prejuicio y el desconocimiento.

Como sostiene Torres (en Luhman, 1998: 17), en nuestro medio, es común el rechazo al trabajo de Niklas Luhmann, bajo la queja de que su teoría resulta demasiado compleja. Ello tiene efectos hondos en el pensamiento sociológico, pues, como señalamos, o se critica a Luhmann desde la falta de comprensión o, sencillamente, se descarta como explicación posible. Esta situación ilumina la necesidad de elaborar ejercicios de 'traducción', de clarificación de la teoría luhmanniana y los recursos que involucra, con el ánimo de entablar diálogos académicos que excluyan perspectivas políticas o morales.

El método funcional, como señalamos, consiste en relacionar varias causas que son funcionalmente equivalentes para producir el mismo efecto, e intenta identificar cuál es el criterio de selección de una causa para producir cierto efecto y con relación a qué función lo cumple. Partir del reconocimiento del carácter abstracto de las funciones y de los problemas de referencia, observar la equivalencia entre las posibles soluciones del mismo, permite una mirada de gran angular, desontologiza, complejiza, transita por 'lugares' que, con el uso de otros métodos, quedan completamente invisibilizados.

En este sentido, reiteramos, a propósito del 'carácter conservador' atribuido al MF, que el funcionalismo no busca justificar algún tipo de efecto y después encontrar una causa que garantice la producción del mismo, más bien, utiliza la referencia a un tipo de efecto particular como estímulo para comparar y equiparar determinados hechos causales. Por ello, no procede a partir de la exclusión de todas las otras causas posibles y la designación de una, sino de la inclusión, pues su pretensión es identificar rendimientos equivalentes en la resolución de problemas particulares de los sistemas sociales.

Esta manera de proceder sólo es posible a partir de una construcción particular del concepto de observación, a saber, observar como el trazo de una distinción, como el ejercicio de sacar algo del unmarked space del mundo, como una operación que no adquiere sustancia alguna, sino que únicamente actualiza un lado de una forma, una forma que siempre aparece como 'invisible' para quien observa y que por ello reclama la perspectiva del segundo orden.

La observación de segundo orden permite identificar la distinción que utiliza el observador de primer orden, con ello es posible clarificar ¿qué es lo que el observador de primer orden excluye cuando utiliza esa distinción?, ¿qué es lo que ésta no le permite ver?, ¿por qué esa distinción y no otra? Dicha estrategia se traduce en una 'crítica' más profunda que cualquiera planteada por las 'teorías marxistas', en el sentido de que presenta una imagen compleja del mundo, que excluye explicaciones unilaterales y simplistas.

Mirar desde el segundo orden, permite acceder a un concepto de realidad que sólo puede ser resultado de una red de observaciones cuya 'consistencia' y validez se explica sólo a partir de su facticidad. Es decir, en la base del orden social no aparece ningún tipo de consenso o instrucción ontológica, sino un entramado de observaciones recursivas.

Pensar, desde la teoría de sistemas, a la sociedad moderna como resultado de una multiplicidad de observaciones permite reconocer que siempre existe 'el otro lado', que quien observa es incapaz de percibir las discontinuidades y las distinciones de las que parte la propia observación, es decir, es incapaz de ver lo que no ve, por tanto, es en este sentido que la observación de segundo orden se convierte en un recurso

Revista Política, Globalidad y Ciudadanía, Vol. 3 No. 5, Enero - Junio 2017, Universidad Autónoma de Nuevo León, Monterrey,

México Monterrey, México, ISSN 2395-8448. pp 15-33. http://revpoliticas.uanl.mx/index.php/RPGyC/article/view/33 
imprescindible en la sociología, pues permite ver lo que el observador de primer orden no puede.

Sólo en este contexto adquieren relevancia las posibles soluciones a los problemas, que no fueron seleccionadas. Bajo este concepto de realidad la noción de contingencia juega un papel central, pues la selección de una solución a un problema de referencia sólo es una entre otras soluciones posibles, es decir, es contingente.

A partir de ello es posible comprender, por un lado, la importancia de la relación entre el método funcional y la observación de segundo orden en la propia teoría luhmanniana y por otro, la relevancia de este binomio para el pensamiento sociológico, en el sentido de que, el MF, permite, también reconocer que su observación es una observación hecha por un observador, en este sentido, puede ser observada.

Finalmente consideramos importante enfatizar que la discusión desarrollada en el presente artículo refuta las críticas (prejuicios) señaladas al inicio de la exposición. Pues frente a la idea de que, por herencia parsoniana, el método funcional de Niklas Luhmann concibe al sistema en términos de orden y equilibrio, por tanto, las estructuras deben mantienen una función estática, es necesario recordar, que tal y como sostiene Galindo (2008: 58) en la reconstrucción que Luhmann elaboró del método funcional, buscó, fundamentalmente, rescatarlo de las premisas del estructural funcionalismo parsoniano.

Mientras que, para Parsons, la existencia del sistema social depende sólo de cuatro funciones, para Luhmann, como ya se demostró, la idea de función y estructura no permanece estática, por el contrario, éstos son vistos como componentes dinámicos que pueden ser transformados. El reconocimiento del dinamismo en el sistema, es decir, de que todo sistema social se compone de elementos basalmente inestables y que en este sentido las estructuras están supeditadas a las operaciones, responde a la segunda crítica, citada en las primeras líneas de este texto, que sostiene que el método funcional descuida el cambio y el 'conflicto'.

Por otro lado, la perspectiva formal del método funcional anula toda noción de actores portadores de funciones; como se especificó, para Niklas Luhmann la función no tiene sustancia, tampoco es un efecto a producir, ésta es únicamente un esquema lógico regulador, que organiza un ámbito de comparación de efectos equivalentes.

Reservamos el final de este artículo a la crítica según la cual el método funcional 'no cumple con los requerimientos mínimos que demanda la ciencia', porque consideramos sustancial, subrayar que pocas rutas de análisis permiten una imagen tan amplia de los problemas sociológicos, como la que logra el método funcional.

La posibilidad de observar las diversas opciones que pueden sustituirse en una relación de equivalencia y logran desparadojizar la paradoja del observador, el ejercicio de comparar diversas observaciones, científicas y cotidianas, la forma problema/ múltiples soluciones equivalentes del problema amplían la visión científica, como no lo había hecho antes ninguna perspectiva. La 'duda metódica' que se logra con la visión funcionalista es una innovación revolucionaria en sociología.

\section{REFERENCIAS}

Arnold, M. y Robles, F. 2000. Explorando caminos transilustrados más allá del neopositivismo. Cinta moebio 7: 49-66

Baecker, D. (2005). Form and forms of communication. Deutschland: Frankfurt am Main, editorial Suhrkamp.

Bateson, G. (1998). Pasos hacia una ecología de la mente, una aproximación revolucionaria a la autocomprensión del hombre. Lohlé-Lumen, Buenos Aires, Argentina.

Bednarz Jr, J. (1984). Functional Method and Phenomenology: the view of Niklas Luhmann. Human Studies, Vol 7, 343-362.

Bobbio, N. (1998). Diccionario de política, Vol 1. Siglo XXI editories. 
Del Angel, J. S. (2008). La autorreproducción del sistema de la ciencia en el campo académico de la comunicación en México. Una reflexión a partir de Niklas Luhmann. Tesis de Doctorado, Universidad Veracruzana, Boca del Río, Veracruz, México.

Estrada S., M. (2007). La comunidad armada rebelde y el EZLN: un estudio histórico y sociológico sobre las bases de apoyo zapatistas en las cañadas tojolabales de la Selva Lacandona, - 1a. ed. — México, D.F.: El Colegio de México, Centro de Estudios Sociológicos, 1930-2005. pp. 623.

Estrada S., M. (2010). Consideraciones finales zapatismos locales. En Estrada S., M. y J.P., Viqueira (2010). Los indígenas de Chiapas y la rebelión zapatista: microhistorias políticas. México D.F.: El Colegio de México, pp. 419-434.

Estrada S., M. \& Y Guerra B., E. (2012). Coda. La perspectiva sistémica para el estudio de los movimientos sociales: ¿sólo otro giro de tuerca? En Estrada S., M. (Coord.) Protesta social. Tres estudios sobre movimientos sociales en clave de la teoría de sistemas de Niklas Luhmann. México: D.f.. El Colegio de México.

Foucault, M. (2010). La arqueología del saber. 2a ed., Siglo XXI, México.

Galindo M., J. (2008). Entre la necesidad y la contingencia: Autoobservación teórica de la sociología. Anthropos, Universidad Autónoma Metropolitana, México.

Günther, G. (1973). Life as Poly-Contexturality. En H. Fahrenbach (Hrsg.), Wirklichkeit und Reflexion, Festschrift für Walter Schulz, 187-210.

Günther, G. (1979). Cognition and Volition A Contribution to a Cybernetic Theory of Subjectivity. Beiträge zu einer opertionsfähigen Dialektik, Band 2, Felix Meier Verlag, Hamburg, pp. 203-240.

Habermas, J. (1990). Pensamento póst-metafísico. Estudos filosóficos/Jürgen Habermas. - Rio de Janeiro: Tempo Brasileiro, 271pp.

Hernández, R., Fernández, C., y Baptista, P. (2014). Metodología de la investigación. México: Mc Graw Hill.

Laclau, E. (1995). The Time Is out of Joint. Diacritics, Vol. 25, No. 2, pp. 85-96.

Lechuga, J. (2018). Necesidades insatisfechas de una comunidad aledaña a una terminal portuaria de Barranquilla. Revista Pensamiento y Gestión, 45 (2) 181-210.

Luhmann, N. (1973). Función y Casualidad en "Ilustración sociológica y otros ensayo. Argentina: Buenos Aires, editorial Sur.

Luhmann, N. (2007). La sociedad de la sociedad (1a ed.). México: Herder, Universidad Iberoamericana, pp. 954.

Luhmann, N. (1992). Entrevista a Niklas Luhmann. En Torres N. Y Zermeño P., Estudios Sociológicos X: $30,1992$.

Luhmann, N. (1995). The Paradoxy of Observing Systems. Cultural Critique, No. 31, The Politics of Systems and Environments, Part II, pp. 37-55.

Luhmann, N. (1996). La ciencia de la sociedad. Universidad Iberoamericana /Editorial Anthropos, 1ed. en español.

Luhmann, N. (1998). Sistemas sociales, Lineamientos para una teoría general. Anthropos Editorial/ Universidad Iberoamericana/ CEJA, Pontifícia Universidad Javeriana, 582.

Luhmann, N. (1998,b). ¿Cómo se pueden observar estructuras latentes? En, Watlawick, Paul; Krieg Peters. El ojo del observador: contribuciones al constructivismo. Barcelona, Gedisa, 1998. p 60-72.

Revista Política, Globalidad y Ciudadanía, Vol. 3 No. 5, Enero - Junio 2017, Universidad Autónoma de Nuevo León, Monterrey, México Monterrey, México, ISSN 2395-8448. pp 15-33. http://revpoliticas.uanl.mx/index.php/RPGyC/article/view/33 
Luhmann, N. (1999). Teoría de los sistemas sociales: Universidad Iberoamericana, artículos II, 1 ed. 233 pp.

Luhmann, N. (2006). Sociología del riesgo. Universidad Iberoamericana, México, D.F., 205 pp.

Luhmann, N. (2007, b). La religión de la sociedad, España, Madrid, 1a. edición en español, Editorial Trotta, $314 \mathrm{pp}$.

Luhmann, N. (2009). Introducción a la teoría de sistemas, lecciones publicadas por Javier Torres Nafarrate, Universidad iberoamericana, tercera reimpresión, México, D.F.

Luhmann, N. (2009, b). Sociología de la religión, Editorial Herder, 1a edición en español, México, D.F.

Marx, K. 1978. Contribución a la crítica a la economía política. Fondo de Cultura Económic

Maturana R, H. (2009). La realidad: ¿objetiva o construida? II, fundamentos biológicos del conocimiento. Anthropos Editorial; México: UNiversidad Iberoamericana: Guadalajara (México): Insituto Tecnológico y de Estudios Superiores de Occidente (ITESO).

Maturana R, H. Y Varela G. F. (2003). De máquinas y seres vivos, autopoiésis: La organización de lo vivo. Buenos Aires, Lumen.

Maturana R, H. Y Varela G. F. (2003, b). El árbol del conocimiento: las bases biológicas del entendimiento humano. Buenos Aires: Lumen, 2003. pp. 208.

Niels A, A. (2003). Discourse Analytic Strategies: Understanding; Foucault, Kosselleck, Laclau, Luhmann, UK, The policy press.

Pintos, J. L. (1999). Sociocibernética: Marco sistémico y esquema conceptual en Métodos y Técnicas cualitativas de Investigación. en Ciencias Sociales, Editorial Síntesis, Madrid.

Pintos, J. L. (2004). Revisión y ampliación de los elementos básicos de la Teoría de los Imaginarios Sociales. Publicado en SEMATA. Ciencias sociales y humanidades, vol. 16, pp. 17-52.

Rasch, W. (1997). Locating the Political: Schmitt, Mouffe, Luhmann, and the Possibility of Pluralism. International Review of Sociology, Vol. 7, No. 1, 103-114.

Spencer B, G. (1979). Laws of form, New York, Dutton, a Division of Elsevier-Dutton Publishing Co., Inc., $143 \mathrm{pp}$.

Stäheli, U. (2008). Figuras rivales del límite; dispersión, transgresión, antagonismo e indiferencia, en Laclau, aproximaciones críticas a su obra, Simon Critchley y Oliver Marchat (Compiladores), 1 Ed. Buenos Aires, Fondo de Cultura Económica, 444pp.

Von Foerster, H. (1991). Las Semillas de la cibernetica. Colección: Terapia familiar, 224 pp.

Wall, D. (2005). Babylon and Beyond, The Economics of Anti-Capitalist, Anti-Globalist and Radical Green Movements. Chase Publishing Services Ltd, Fortescue, Sidmouth, EX10 9QG, England.

Zamorano F., R. (2008). Debate en torno a las concepciones del tiempo en sociología. Chile, Santiago, Cinta de Moebio, Universidad de Chile, marzo, número 031, pp. 53-69. 